\title{
COMMENTARY
}

\section{The renaissance of online medical education}

\section{AUTHOR}

Efrat Zamir ${ }^{1}$ Medical Student *

\section{CORRESPONDENCE}

*Ms Efrat Zamir efratmendel@mail.tau.ac.il

\section{AFFILIATIONS}

${ }^{1}$ Sackler School of Medicine, Tel Aviv University, Tel Aviv, Israel

\section{PUBLISHED}

7 September 2021 Volume 21 Issue 3

HISTORY

RECEIVED: 12 June 2020

REVISED: 19 June 2021

ACCEPTED: 27 June 2021

\section{CITATION}

Zamir E. The renaissance of online medical education. Rural and Remote Health 2021; 21: 6187. https://doi.org/10.22605/RRH6187

\section{ETHICS APPROVAL}

Not relevant.

This work is licensed under a Creative Commons Attribution 4.0 International Licence

\section{ABSTRACT:}

The emergence of the COVID-19 pandemic has forced a change in medical education in Israel. The suspension of clinical clerkships has set in motion the implementation of online lectures. Tutors have been able to teach from their wards, continue to be available for urgent patient care, and students have been able to learn uninterruptedly and safely at their homes. According to previous

\section{Keywords:}

COVID-19, e-learning, learning style, medical education, medical students.

\section{FULL ARTICLE:}

\section{Introduction}

The COVID-19 pandemic emerged in Israel on March 2020 and the clinical rotations for medical students were suspended. Many studies, learning online can be compatible with recommended learning techniques such as space repetition, which allows students to accumulate knowledge in the most effective way for them according to their learning needs and preferences. This can enhance their learning experience and maintain long-term memory. 
debate regarding the return of the medical students to the clinical clerkships. There were concerns that it might increase their risk for exposure to the virus and compromise the health and safety of patients. Estimates suggest that about $80 \%$ of people with COVID-19 have mild or asymptomatic disease and, on the basis of few clinical virological studies, the infectious period for COVID-19 might last for 10 days or more after the incubation period. Medical students may be exposed at hospitals and unknowingly transmit to others, further spreading the virus ${ }^{3}$. Unfortunately, further suspension of medical education for a longer period of time might delay the next generation of doctors in Israel.

To balance the risk of unnecessary exposure of medical students to the virus with the need to preserve the routine of studying and the continuation of medical education, online medical lectures were administered before attending bedside sessions, allowing time spent at the hospital wards to be minimal but effective. Most of the Israeli adult population is now vaccinated and herd immunity may have been reached $\mathbf{4}$, and online lectures remain an integral part of higher education in Israel - yet they are not implemented in most medical higher education programs. The integration of online lectures is still very limited, and implemented only in specific medical fields.

Medical education, especially during clinical clerkships, is unique. Medical students learn not only the clinical concepts, but also develop as physicians, as they navigate the clinical learning environment ${ }^{\mathbf{5}, \mathbf{6}}$. As described by professor of medical education FW Hafferty, 'a great deal of what is taught - and most of what is learned - in medical school takes place not within formal course offerings but within medicine's 'hidden curriculum" ${ }^{\prime \mathbf{7}}$. There is no doubt the traditional learning method of a direct clinical exposure during clinical clerkships is irreplaceable, yet it can be much improved and modernized via online methods.

\section{The online learning environment}

Online learning allows students to watch online lectures conducted by practicing physicians in their comfort zone at home without interruptions, transcribe the lecture, record it and listen to it when it suits them, at their own pace. It also allows the students to relisten to lectures containing many new facts and concepts. During the pandemic, students have been able to stay connected, despite social distancing, and preserve the routine of learning regardless of their geographic location.

\section{Online lectures and academic performance}

An example of the implications of online medical lecture for student academic performance was demonstrated in a study by Prunuske et al, where a series of short online lectures was integrated into the homework assignments of a large, introductory biology course in a research university. The majority of students opted to view the lectures before coming to class and reported it helped them to complete in-class activities. Furthermore, students who viewed the online lectures performed better on an exam designed to test lower order cognitive skills ${ }^{8}$. Novel studies conducted during the COVID-19 pandemic demonstrated an improvement of clinical skills using online methods ${ }^{\mathbf{9}, \mathbf{1 0}}$ including virtual rotations $s^{4,7,11,12}$.

\section{Space repetition}

Online medical video lectures also allow space repetition. As described by Augustin, one of the main factors in successful learning is recalling information in expanding intervals. This might be accomplished by active recall or repetition of specific online lectures ${ }^{\mathbf{1 3}}$. Spaced learning, defined as learning sessions spaced over time and including repeated information, is already applied across health profession education in varied methods, with most of them involving online learning. Space repetition results in more efficient learning and retention compared to massed educational methods and generates significant improvements in longer term information retention ${ }^{\mathbf{1 4}}$.

\section{Study according to preferred learning style}

Learning style, the way in which a person accumulates knowledge in the most effective way, can be divided according to sensory personal preferences. According to Fleming and Mills, the most common learning styles are visual, auditory and kinesthetic. Visual learners prefer information presented as graphs and symbols or printed as words. Auditory learners learn best from listening. They would rather hear the information presented and they often repeat what is said or rephrase the information into a question for discussion. Kinesthetic learners learn best from experience and practice, which is usually multi-modal and might involve all perceptual modes: sight, touch, taste, smell and hearing ${ }^{15,16}$.

In a study conducted by Busan, about a third of the medical students were visual learners (33\%), a third were auditory learners (26\%), and a third preferred a combination of methods $(27 \%)^{\mathbf{1 6}}$.

Online medical lectures can address the majority of students as they encompass both auditory and visual information. Although there is no evidence that learning according to preferred learning style can enhance learning, it has an empowering effect that cannot be ignored $\mathbf{1 7}^{\mathbf{1 7}}$. It has also been found that highly motivated students are more likely to use online medical lectures ${ }^{16,18,19}$. In a survey of 39 higher education institutions in the US, 29 of these (72\%) taught learning style theory as part of faculty development for online teachers ${ }^{\mathbf{2 0}}$.

\section{The health professional educators' point of view}

From the health professional educator's point of view, online teaching provides another avenue to highlight important concepts, use animations and short videos embedded in the presentation for emphasizing a point or idea. When teaching online, small breakout groups can be formed within a video-conferencing platform such as Zoom, allowing the educator to reach students that may not usually stand out in class. The online lecture format can be set up easily using pedagogical materials available on the instructor's personal laptop. Online lectures can be recorded and distributed offline to a larger number of students and allow the continuity of medical education, even if the availability of the tutor is compromised due to increased demand in hospital care, and in 
extreme cases such as during the COVID-19 pandemic.

Furthermore, online lectures can be updated in a timely manner to ensure delivery of the latest evidence-based content.

\section{Conclusions and outlook}

The current generation of medical students has grown up in the digital age. The digital technologies used daily by students can easily be repurposed for learning. In a study by Gormley et al, the majority of medical students reported good access to computers and to the internet, both on and off campus ${ }^{\mathbf{2 1}}$. There are currently many free online resources such as podcasts, blogs, tweets ${ }^{\mathbf{1 4 , 2 2}}$ and YouTube channels, with increasing numbers of subscribers worldwide using them to improve their learning experiences ${ }^{\mathbf{2 3}}$. Face-to-face communication between medical students, tutors and direct patient care is invaluable ${ }^{\mathbf{7 2 4}}$; however, it can be adjusted in ways that complement information technology improvements, expanding medical knowledge and the changing nature of learners.

Although difficult to quantify, overall medical students feel that online education has a positive impact on the learning of clinical skills when compared to traditional forms of learning 21,25-29. Incorporation of online teaching methods within traditional medical education has the potential to maximize students' learning and engagement. The COVID-19 pandemic has changed the way we socialize, work, travel and use technology, and it has changed outpatient medical care by offering virtual appointments ${ }^{30}$. It will probably make its mark on medical education too.

\section{REFERENCES:}

1 Gallagher TH, Schleyer AM. 'We signed up for this!' - student and trainee responses to the covid-19 pandemic. New England Journal of Medicine 2020; 382: e96. DOI link

2 Bauchner H, Sharfstein J. A bold response to the COVID-19 pandemic. JAMA 2020; 323(18): 1790-1791. DOI link

3 Anderson RM, Heesterbeek H, Klinkenberg D, Hollingsworth TD. How will country-based mitigation measures influence the course of the COVID-19 epidemic? Lancet 2020; 395(10228): 931-934. DOI link

4 The Times of Israel. Israel may have reached a 'sort of herd immunity' from COVID, expert says. Available: web link (Accessed 17 June 2021).

5 Scheele F. The art of medical education. Facts, Views \& Vision in ObGyn 2012; 4(4): 266-269.

6 Bandini J, Mitchell C, Epstein-Peterson ZD, Amobi A, Cahill J, Peteet J, et al. Student and faculty reflections of the hidden curriculum. American Journal of Hospice and Palliative Medicine Care 2017; 34(1): 12 November. DOI link

7 Hafferty FW. Beyond curriculum reform: Confronting medicine's hidden curriculum. Academic Medicine 1998; 73(4): 403-407. DOI link

8 Prunuske AJ, Batzli J, Howell E, Miller S. Using online lectures to make time for active learning. Genetics 2012; 192(1): 67-72. DOI link

9 Kasai H, Shikino K, Saito G, Tsukamoto T, Takahashi Y, Kuriyama $A$, et al. Alternative approaches for clinical clerkship during the COVID-19 pandemic: online simulated clinical practice for inpatients and outpatients - a mixed method. BMC Medical Education 2021; 21(1): 149. DOI link

10 Sukumar S, Zakaria A, Lai CJ, Sakumoto M, Khanna R, Choi N. Designing and implementing a novel virtual rounds curriculum for medical students' internal medicine clerkship during the COVID-19 pandemic. Journal of Teaching and Learning Resources 2021; 17: 11106. DOI link

11 Wendt S, Abdullah Z, Barrett S, Cyrus Daruwalla, BSA, Go JA, Le $B$, et al. A virtual COVID-19 ophthalmology rotation. Survey of

\section{Ophthalmology 2021; 66(2): 354-361. DOI link}

12 Ruthberg JS, Quereshy HA, Ahmadmehrabi S, Trudeau S, Chaudry E, Hair B, et al. A multimodal multi-institutional solution to remote medical student education for otolaryngology during COVID-19. Otolaryngology-Head and Neck Surgery (United States) 2020; 163(4): 707-709. DOI link

13 Augustin M. How to learn effectively in medical school: test yourself, learn actively, and repeat in intervals. Yale Journal of Biology and Medicine 2014; 87(2): 207-212.

14 Huddart D, Hirniak J, Sethi R, Hayer G, Dibblin C, Rao BM, et al. \#MedStudentCovid: how social media is supporting students during COVID-19. Medical Education 2020; 54(10): 951-952. DOI link

15 Fleming ND, Mills C. Not another inventory, rather a catalyst for reflection. To Improve the Academy Journal 1992; 11(1): 137-155. DOI link

16 Buşan A-M. Learning styles of medical students - implications in education. Current Health Sciences Journal 2014; 40(2): 104-110.

17 Newton PM. The learning styles myth is thriving in higher education. Frontiers in Psychology 2015; 6: 1908. DOI link

18 Nieder GL, Borges NJ, Pearson JC. Medical student use of online lectures: exam performance, learning styles, achievement motivation and gender. Medical Science Educator 2011; 21(3): 222-228. DOI link

19 O'Mahony SM, Sbayeh A, Horgan M, O'Flynn S, O'Tuathaigh CMP. Association between learning style preferences and anatomy assessment outcomes in graduate-entry and undergraduate medical students. Anatomical Sciences Education 2016; 9(4): 391-399. DOI link

20 Meyer KA, Murrell VS. A national study of theories and their importance for faculty development for online teaching. Online Journal of Distance Learning Administration 2014; 17(2). DOI link

21 Gormley G, Collins K, Boohan M, Bickle I, Stevenson M. Is there a place for e-learning in clinical skills? A survey of undergraduate medical students' experiences and attitudes. Medical Teacher 2009; 31(1): e6-e12. DOI link 
22 Melvin L, Chan T. Using Twitter in Clinical Education and Practice. Journal of Graduate Medical Education 2014; 6(3): 581-582. DOI link

23 AIMS Education. 20 best medical YouTube channels to follow this year. Available: web link (Accessed 19 June 2021).

24 Lempp H, Seale C. The hidden curriculum in undergraduate medical education: qualitative study of medical students' perceptions of teaching. BMJ 2004; 329(7469): 770-773. DOI link

25 Borges NJ, Manuel RS, Elam CL, Jones BJ. Comparing millennial and generation $\mathrm{X}$ medical students at one medical school.

Academic Medicine 2006; 81(6): 571-576. DOI link

26 Han H, Nelson E, Wetter N. Medical students' online learning technology needs. Clinical Teacher 2014; 11(1): 15-19. DOI link
27 Grant J, Owen H, Sandars J, Walsh K, Richardson J, Rutherford A, et al. The challenge of integrating new online education packages into existing curricula: a new model. Medical Teacher 2011; 33(4): 328-330. DOI link

28 Khurana MP. Learning under lockdown: navigating the best way to study online. BMJ 2020; 369: m1283. DOI link

29 Tackett S, Slinn K, Marshall T, Gaglani S, Waldman V, Desai R. Medical education videos for the world: an analysis of viewing patterns for a YouTube channel. Academic Medicine 2018; 93(8): 1150-1156. DOI link

30 Licurse A, Fanning K, Laskowski K, Landman A. Balancing virtual and in-person health care. Available: web link (Accessed 16 June 2021).

This PDF has been produced for your convenience. Always refer to the live site https://www.rrh.org.au/journal/article/6187 for the Version of Record. 